Published by the University of KwaZulu-Natal https://journals.ukzn.ac.za/index.php/JICBE

(C) Creative Commons With Attribution (CC-BY)

Journal of Inclusive cities and Built environment. Vol. 1 Issue 2

How to cite: Tsoriyo et. al. 2021. The Manifestation of Street Safety and Security as Spatial (In)Justice in Selected Small Rural Towns of Vhembe District, South Africa. Journal of Inclusive cities and Built environment. Vol. 1 Issue 2, Pg 1-14.

\title{
THE MANIFESTATION OF STREET SAFETY AND SECURITY AS SPATIAL (IN)JUSTICE IN SELECTED SMALL RURAL TOWNS OF VHEMBE DISTRICT, SOUTH AFRICA
}

\author{
By W. W., Tsoriyo, E. Ingwani, J., Chakwizira and P. Bikam
}

Published 25th October 2021

\begin{abstract}
Safe and secure street spaces for pedestrians translate to spatially just urban environments. This study examined pedestrians' safety and security elements on street spaces in three selected Small Rural Towns (SRTs) in South Africa and assessed the users' physical perceptions of street safety and security in SRTs and their implications on spatial (in)justice. Forty-three street spaces from three SRTs in South Africa were purposively sampled and assessed in this study. The study adopted a mixed-method approach and a street safety spatial (in)justice case study survey design. Data were collected through key informant interviews, a questionnaire survey and observations. The distribution of safety and security elements across the studied 43 street spaces reflect the existence of justices and injustices concurrently. Users' theoretical perception of the meaning of street safety differs significantly from their actual experiences. The study recommends that the design and management of streets be informed by users' vision of street safety and security and innovative project financing strategies by local municipalities to ensure spatial justice on street spaces.
\end{abstract}

KEY WORDS safety and security, street spaces, street users, spatial justice, small rural towns

Corresponding email: mandazawendy@gmail.com 


\section{INTRODUCTION}

Street safety and security and the emergent spatial (in)justices are observable and experiential phenomena. Urban safety and security affect the livability of the urban environment. As Moroni (2020) argued, safety and security on the streets affect users' right to safe public space. Furthermore, safety and security on the streets form the baseline for urban economies. Safe and secure streets retain more users, thereby generating more social and economic activities compared to insecure streets (Bivina and Parida, 2019; Mustafa et al., 2017). It also forms the centrepiece for other development goals such as social inclusivity and citizens' quality of life improvement (SACN, 2019; Wright and Ribben, 2016). Inclusivity, users 'right to safe urban spaces, equity, positive performing spatial qualities are some of the key tenets of street spatial justice (Tsoriyo, 2021). Through providing safety and security on street spaces, the key tenets of spatial justice are simultaneously facilitated on street spaces. Therefore, street safety and security is an important measure of spatial justice in urban spaces. Spatial justice on street spaces is defined as "the fair and equitable distribution of socio-spatial qualities on street spaces [such as safety and security]; enhanced 'Right to the City' claims of the least advantaged users as they interact with street spaces, and the redress of spatial imbalances emanating from street design and management processes" (Tsoriyo,2021:64).

Cozens (2011:481) posits that safety and security "represent endemic problems for post-industrial urban societies". It has become a policy issue for governments globally as well as regionally and locally (World Bank, 2011; South Africa Cities Network (SACN), 2019). Countries such as the United States of America and Australia are adopting principles of newurbanism and engaging in integrated Public-Private Partnerships to deal with issues of crime in the city (Cozens, 2011). In Egypt, the government has resorted to privatisation and militarisation of public space (Mustafa et al., 2017). Privatisation of public spaces through fencing and gating has also become a popular design response to safety and security in South African urban spaces (Landman, 2010). Researchers concur that the increase in crime and violence is a result of urbanisation (Cozens, 2011; Mustafa et al., 2017). Urban poverty has further perpetuated crime and violence in Africa and Latin America (World Bank, 2011). For example, In Colombia and El Salvador, crime gangs are dominant in poor neighbourhoods that are characterised by dilapidated social services (World Bank, 2011). In Cairo- Egypt, the increase in crime and violence is a result of its high population as a megacity and also its iconic place in the Middle East (Mustafa et al., 2017:5).

South Africa is one of the nations with the highest crime rates in the world (SACN, 2019). Robbery cases in South Africa at non-residential places increased by $21 \%$ between 2012 and 2019 (SA Cities Urban Safety Reference Group, 2020). In response, the South African Government prioritises urban safety and security as a key development agenda in South Africa (Ministry of Cooperative Governance and Traditional Affairs (COGTA), 2016). The safety and security imperatives are reflected in several legislations such as the Integrated Urban Development Framework of 2016, Draft White Paper on Safety and Security 2016, Non-Motorised Transport Facility Guidelines of 2014, Spatial Planning and Land Use Management Act (SPLUMA) 16 of 2013, National Development Plan 2012, Manual for Crime Prevention through Planning and Design (2001) (Department of Human Settlements (DHS), 2019; SACN, 2019). These instruments emphasise that environmental design can create safe human settlements and reduced fear of crime (Council for Scientific and Industrial Research 2016; Government of South Africa 2016). For example, the Manual for Crime Prevention through Planning and Design stresses that planning and environmental design should consider these key focal areas: (i)vacant land (ii) 24-hour land use (iii) pedestrian use of infrastructure (iv) equitable provision of facilities ( $v$ ) equitable distribution of facilities such as public spaces and (vi) urban renewal to strategically address safety and security in the urban space (Wright and Ribben, 2016).

This paper focuses on the safety and security of street spaces of SRTs. This is because streets are the most used public spaces in SRTs (SACN, 2014). This paper assumes that safetyconscious design and management of street spaces in South African's SRTs is likely to create more spatially just urban environments. The study has two key objectives which are: (i) to examine the distribution of pedestrian safety and security elements on street spaces in three selected small rural towns (SRTs) in South Africa, and (ii) to assess the users' perceptions of street safety and security in SRTs and their implications on spatial (in)justice. The study tests the hypothesis that there is a statistically significant difference between the users' theoretical meaning of street safety and security and their actual satisfaction with this quality as they use the street spaces.

Small Rural Towns is a South African generated concept that describes small towns that serve a predominantly agrarian rural population (SACN, 2014). SRTs are vital urban spaces that can address rural poverty and inequalities as they act as service and welfare distribution points to the rural communities. SRTs can invigorate the growth of rural non-farm activities and other post-productivity forms of investments (Reynolds and Antrobus, 2012). They stimulate employment through Small, Medium and Micro Enterprises (SMMEs). However, dynamic changes have occurred in both the urban and the rural landscape at both global and local scales. For example in terms of the economy, SRTs have shifted from an agrarian to a monetised economy (SACN, 2014). The real estate market is also expanding in the SRTs, resulting in increased population and greater demand for use of public spaces such as streets (Bolay, 2015). As such, ensuring spatial justice through street safety and security is imperative as it affects the 
street users' right to enjoy safe public space in SRTs. There is no consensus on the average urban population of SRTs, but generally, local researches show that they have an urban population of fewer than 100000 people (SACN, 2014; Donnaldson and Marias, 2012; Reynolds and Antrobus, 2012; Artkinson, 2008). Local municipalities administering the SRTs are usually underfunded, yet they are the sole providers of service delivery that is supposed to facilitate spatial justice in the towns (United Cities and Local Governments (UCLG), 2013). There is a glaring absence of studies that interrogate spatial justice on street spaces in SRTs, although this is an important place-making concept. According to Hoogendoorn and Visser (2016), most SRTs in South Africa are historically marginalised and some of the spatial injustices inherently flow from the country's apartheid spatial planning history. Therefore, interrogating spatial justice on street spaces in SRTs is vital in contributing to the literature on placemaking and the social sustainability of marginalised areas.

This study comprises six main sections. The proceeding second section is the literature review section. The literature review explores the study's main concepts: street safety and security, street and street users, spatial (in) justice, and small rural towns. The third section discusses the methodology employed in the study, followed by the presentation of results in the fourth section. The fifth section provides a discussion of the research findings. The last section concludes the study and provides recommendations that other local municipalities with similar conditions can adopt.

\section{LITERATURE REVIEW}

\subsection{Street Safety and Security}

Street space safety is defined as the security of people from risks and vulnerabilities, including robbery, theft, terrorism, traffic accidents and all sorts of abuse (Mustafa et al. 2017; Shaftoe 2008). People meet, move and make meaning of space on streets (Mehta and Bosson 2018); hence, streets should offer safety and security to the users. The right to safe public spaces is an essential right to the city claim (Moroni, 2020), which translates to spatially just streets. Urban design theory and practice advance several determinant factors as measures to improve pedestrian safety and security on the streets. Urban designers highlight the (i) presence of police presence on streets, (ii) design of streets in a way that encourages continuous use, (iii) clear demarcation and separation of public and private spaces, (iv) clearly- marked pedestrian crossings, and ( $\mathrm{v}$ ) increasing "eyes in the streets" and (vi) street lighting as some of the key basic requirements that should be used to evaluate street safety and security (Smith and do Santos, 2019; Wright and Ribben, 2016; Jacobs 1961). There exist contradictions in the literature concerning these indicators of measuring street space safety and security (Anderson, 2011). Bivina and Parida (2019) posit that police presence offers the reassurance of safety and security for street users. Contrary, Shaftoe (2008) urges that police presence may be intimidating for users, hence proposing that municipalities employ street ambassadors who patrol the street spaces. Mistrust in the police system often results in street users taking greater responsibility for their safety on the streets (Anderson, 2011).

"Eyes on the streets"1 can be enhanced by orienting buildings towards streets, ensuring continuous movement, diversity of activities, other street users' presence, and adequate street lighting (Bivina and Parida, 2019). Contemporary researchers also argue that the "eyes on the streets" should go beyond design by ensuring that citizens are involved in the decision-making process (Goodyear, 2013). Some scholars express different views on the presence of other street users as a measure of safety and security

\footnotetext{
Eyes on the street is a concept coined by Jacobs (1961) which describes engaging activities along the street which encourage more pedestrian use on the streets thereby providing natural surveillance.
}

(Wright and Ribben, 2016). The presence of other users does not guarantee the safety and security of other street spaces users. For instance, Shaftoe (2008) argues that the social-cultural differences in cosmopolitan societies require going beyond other users' mere presence to the users' similarity. Users' similarities can be determined by age, gender or race, resulting in some parts of the streets being dominated by different groups. For example, the elderly might feel more secure in places where there are similar users and less secure in sections dominated by the youths. Thus, perceptions of safety and security go beyond physical design features to include other subjective socialdemographic considerations.

The value of street lighting is subject to street user's psychological perceptions of the safety and security of a particular street. Bivina and Parida (2019) argue that street lighting encourages more users to venture into the streets at night. However, crime and victimisation incidents are common in inadequately lit street sections (Wright and Ribben, 2016). The presence of lighting in itself does not guarantee safety. The extent to which lighting instils a sense of security and safety among street users is subject to other factors such as users' perceptions. Clearly-marked crosswalks accommodate pedestrians alongside motor vehicles (Kott, 2011). As put forward in Hartman and Prytherch (2015), marked crossroads attempt to amend the "streets designed for cars into streets for people". Pedestrian crosswalks can reduce accidents and related hazards in motorised streets, though they cannot guarantee pedestrian safety to visually impaired street users (Imrie, 2012). Marked crossings are less adaptive than new thinking of promoting safety through shared streets (HamiltonBaillie, 2008). The concept of shared streets emphasises the utilisation of placemaking strategies to enhance driver engagement in space. It thereby leads the drivers to intuitively reduce speed to enable sharing of the street with pedestrians. 
Weber and Podnar Žarko (2019) argue that closed-circuit television (CCTV) and sensors enhance street space safety by improving the visibility of perpetrators. However, Fyfe and Bannister (1998) view it as a cosmetic measure that cannot stop criminals from committing a crime. Thus, a surveillance camera's role in enhancing security on the streets is also a contradictory measure of street safety and security. There are disagreements on the extent to which individual elements enhance safety and a sense of security among street users. Apart from urban design elements, safety and security are subject to individual user's perceptions (Goodyear, 2013). According to Cozens (2011:481), a "sustainable community is both safe and perceived by its residents to be safe from crime". Since users' perceptions vary, there is not a straightforward way of measuring the concept of safety and security in street spaces. Therefore it is important to analyse this complex issue through a multi-dimensional approach (Carmona et al., 2003).

\subsection{Unpacking the streets and their users}

Streets are linear three-dimensional spaces enclosed on opposite sides of the buildings (Carmona et al., 2003:146). According to LoukaitouSideris and Ehrenfeucht (2009), the road carriageway and sidewalks are the main elements that make up a street. Streets are integral elements forming the spatial framework of the city, as they perform various physical, economic and social functions (Mehta and Bosson, 2018). The road carriageway and sidewalks are the main elements that make up a street (DHS, 2019; Loukaitou-Sideris and Ehrenfeucht, 2009). Street space users are classified as vehicular and non-vehicular users (Hartman and Prytherch, 2015). In some cases, street space users are described according to various social constructs such as age, gender and race (Rezafar and Turk, 2018). Hartman and Prytherch (2015) express that streets' design is predominantly vehicular-oriented at the expense of the needs of pedestrians.
Thus, the pedestrians represent the most disadvantaged category of street space users. Moreover, street space users have different experiences, needs and expectations on street spaces. In most cases, however, the design of streets prioritises the physical movement function of the streets to the detriment of other social interactive activities such as seating and meeting (Moroni, 2020). Resultantly spatial injustices emerge due to limited social interactions in street spaces. According to Lefebvre (1996), the unavailability of social functions on the streets negatively affects their use value (Lefebvre 1996). This also translates to spatial (in)justice because ideal public spaces are multi-functional.

\subsection{Exploring the concept of spatial (in)justice}

The contradistinctions that exist in defining street safety and security measures equally exist in defining spatial (in)justice. This is because the spatial (in)justice phenomena is a multidimensional concept that can be both observed in space and experienced disparately by different users. Spatial justice is defined by Soja (2009:2) as the "fair and equitable distribution of socially valued resources and the opportunities to utilise them". Williams (2013:4) defines spatial justice as a set of material and ideological relations that act on space yet are guided by social ties. In the context of South Africa, Adegeye and Coertzee (2019:387) conceptualise spatial justice as "the spatial distribution of socially valued resources (i.e. education, employment, transport, health and housing), in such a way that everyone has adequate access, with the disadvantaged of the society being the first beneficiaries". Spatial justice is attainable through promoting principles of diversity, democracy, equity and a just distribution based on merit or need (Adegeye and Coertzee, 2019:387). Space is a medium for distributing (in)justice, and it creates or sustains (in)justice (Soja 2009). Space is both the content and context of spatial (in)justice (Williams, 2013). Spatial injustice is the unevenness in distributing particular social, economic, political or environmental traits in geography (Erdiaw-Kwasie and Basson, 2018). Space plays a central role in producing and even distributing (in)justices, and space is often inconspicuous in academic debates on justice (Soja, 2009). Studies on spatial justice often focus on other forms of justice, such as environmental, economic and social (Harvey, 2012).

Various processes produce and reproduce spatial (in)justice. Van Wyk (2015) suggests that it is a product of spatial development policies and regulations, street management philosophies, judiciary interventions, strategies, plans and other social movements. For example, urban regeneration programmes can result in the reconfiguration of spatial (in) justice by altering the distribution and quality of facilities across space either positively or negatively (Dirsuweit, 2009). Street management philosophies such as privatisation of public space reduce streets' status and thus impact the users' perceptions of justness (Carmona et al., 2003; Hartman and Prytherch, 2015). Spatial justice is a multifaceted phenomenon that has unclear measurable parameters and solutions (Adegeye and Coertzee, 2019). However, spatial justice can be observed through the distribution of safety and security determinants or qualities along a street and experienced differentially by users of street spaces.

\section{METHODOLOGY}

The study utilised multiple case studies and a survey. It employed a mixed-methods approach, using both quantitative and qualitative methods during data collection and analysis. The study population includes all street spaces in the CBDs of the selected SRTs, non-vehicular street space users (hereafter referred to as street users) and key experts in spatial planning in Vhembe District. 
The case studies from three SRTs of Thohoyandou, Musina and Louis Trichardt in Limpopo Province of South Africa were purposively sampled². Thulamela, Musina and Makhado Local Municipalities administer these towns respectively. We used a total population of forty-three streets (i.e., 36 access streets, 4 local distributors, 2 provincial roads and 1 national road) of different hierarchies from the central business districts. In Thohoyandou Town, we selected twenty-three street spaces, ten streets from Musina Town and ten streets from Louis Trichardt Town.

To interrogate how users perceived street safety and security in the SRTs, we surveyed 500 street space users' from the three case study towns. The initial sample size of 384 street users was obtained by using the sample size calculation formula ${ }^{3}$ by Fowler (2012). To allow for diversity of perceptions, we oversampled the street users by $30 \%$ from the initial 384 to 500 . The total population proportion for each town was used to determine the sample size of street space users from each case study town as illustrated in Table 1.

Table 1: Sample size for street users

\begin{tabular}{|l|l|l|l|}
\hline Study area & $\begin{array}{l}\text { Urban } \\
\text { Population }\end{array}$ & $\begin{array}{l}\text { Population } \\
\text { proportion }\end{array}$ & Sample size \\
\hline Thohoyandou & 69453 & $51 \%$ & 255 \\
\hline Musina & 42678 & $31 \%$ & 155 \\
\hline Makhado & 25360 & $18 \%$ & 90 \\
\hline Total & $\mathbf{1 3 7 4 9 1}$ & $\mathbf{1 0 0 \%}$ & $\mathbf{5 0 0}$ \\
\hline
\end{tabular}

Source: Tsoriyo (2021:100)

Due to the fluidal nature of the street users,' we employed quota sampling as a strategy for recruiting the study sample ${ }^{4}$. Gender was the main determining factor for this sampling approach. According to the community survey of 2016, females in Vhembe District are $53 \%$, while males are $47 \%$ (StatsSA, 2018). This same proportion was used in the selection of the participants. Eight spatial planning experts knowledgeable on street design and management (6 from the three local municipalities of the SRTs, one from Vhembe District Municipality and one from University of Venda Urban and Regional Planning Department) were purposively sampled.

Data were collected through observations (guided by the street space design checklist), structured interviews with key experts and a questionnaire survey administered to 500 street users. Three research experts ${ }^{5}$ who were involved in collecting data on the quality of street safety and security indicators using a street space design checklist. The measurable indicators (drawn from meta-synthesis of various literature sources) used were (i) clearly- marked street crossings for pedestrians, (ii) adequacy of street lights $^{6}$, (iii) presence of surveillance cameras, (iv) presence of police, (v) visibility of human activities from the street edge, and (vi) continuity of pedestrian movement. These indicators are the basic requirements needed for streets to be safe and secure spaces. The expert measured the quality of street safety and security indicators on a

\footnotetext{
2 These SRTs were selected based on their location in a rural province, in the same district municipalityVhembe. The 3 local municipalities usurp guidelines on managing street spaces from common policies and structures. They all have demographic profiles of less than 100000 urban population (see Table 1) $n=\frac{z^{2} \cdot p \cdot q}{e^{2}}$

4 The street users were selected on a convenience basis depending on the street space users' willingness to participate in a 40-minute long survey.

5 The research experts comprised two town planners and an urban designer

6 The observation on street lighting was made during the early evening hours of between 1800pm $-1900 \mathrm{pm}$. The key assumption being well-lit streets that are without dark spots at night ensure safety
}

5-point Likert scale (where 1 represents a least performing quality and 5 is an outstanding quality). The quality of safety and security elements being measured explains the extent to which street spaces in SRTs reflect justice or injustice. Where the quality of a specific element is poor, then a street is spatially unjust regarding the particular element. An outstanding quality on the other hand is a form of spatial justice. The design standards from various spatial planning instruments such as the Guidelines for Human Settlement Planning and Design, the Neighbourhood Planning and Design Guide, Road Access Guidelines, National Technical Requirements informed the ranking of these basic safety and security requirements. Pedestrian headcounts at nodal points were done during off-peak hours (between 1030am and 1130am and between $1430 \mathrm{pm}$ and $1530 \mathrm{pm}$ ) to measure the continuity of pedestrian movements on the streets.

Data were analysed using both qualitative and quantitative methods. Qualitative data were analysed using thematic analysis. Quantitative data were analysed using Stata version 14 . Quantitative data was in the form of mean satisfaction scores and the Wilcoxon rank-sum test. The Wilcoxon rank-sum test was used for testing the study hypothesis (see Introduction section). Radar charts (web diagrams) were used to present findings on street safety features per town ${ }^{7}$. The researchers compared the distribution of safety and security elements across the towns through hierarchical cluster analysis $(\mathrm{HCA})^{8}$. The study adopted the nonparametric agglomerative hierarchical clustering (AGNES) approach.

\footnotetext{
Radar charts show how each indicator of street safety performed in comparison to other indicators. The performance of the indicator is ranked from very poor to very high.

8 HCA determines the number of safety and security clusters emerging so that street design and management efforts are channelled toward street spaces with poor cluster performance.
} 


\section{RESULTS}

This section presents the key findings of the study as informed by the main objectives of the study.

\subsection{The distribution of pedestrian safety and security elements on street spaces in the SRTs}

The findings reveal that both similarities and variations exist in the quality level of various street safety and security measures within the same town as well as between towns. For example, in the case of Thohoyandou Town, the quality of human activities was poor in some cases ( $26 \%$ of the streets), while outstanding in others $(26 \%)$. In Musina Town, this quality was outstanding in $50 \%$ of the streets. Louis Trichardt on the other hand had $90 \%$ of its street reflecting poor human activities.

Figures 1, 2 and 3 show the results on the quality of safety and security indicators of the three respective SRTs.

Figure 1: Quality of Safety and Security Features in Thohoyandou Town

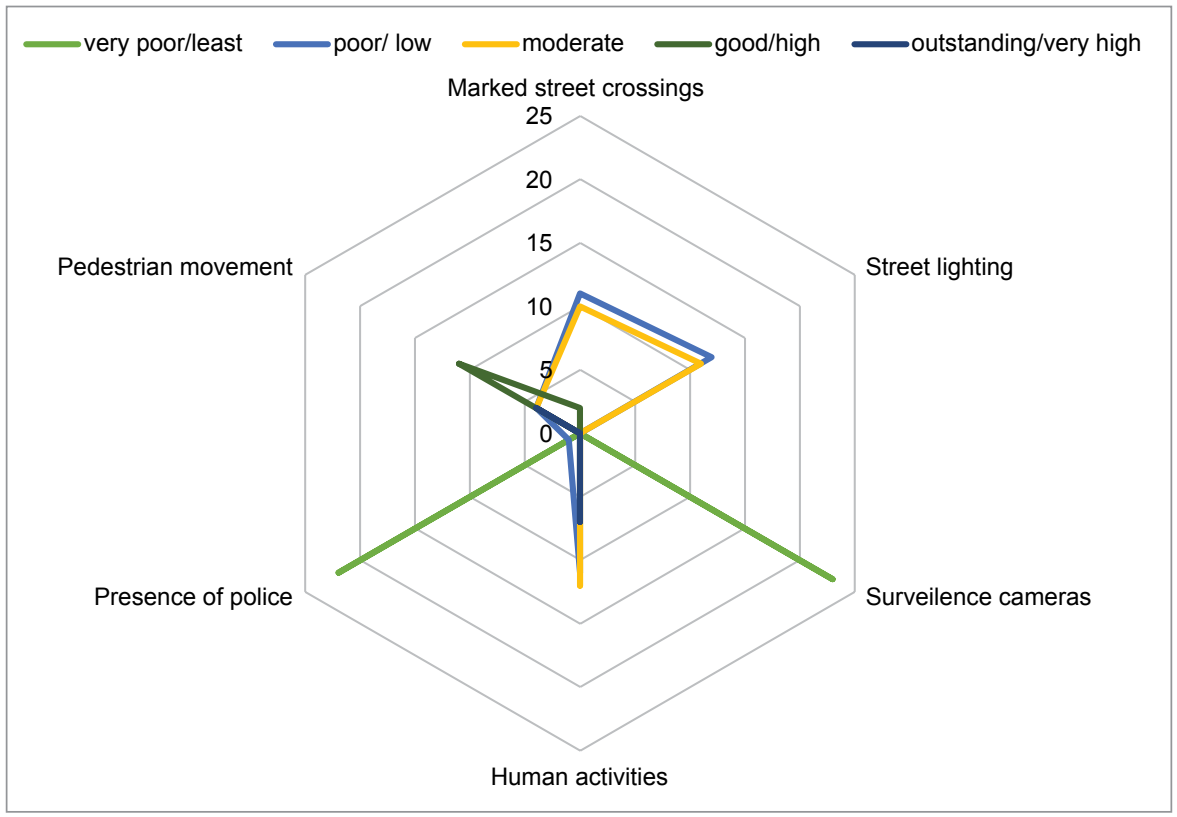

Source: Research survey (2020)

Figure 2: Quality of Safety and Security Features in and Security Features in Musina Town

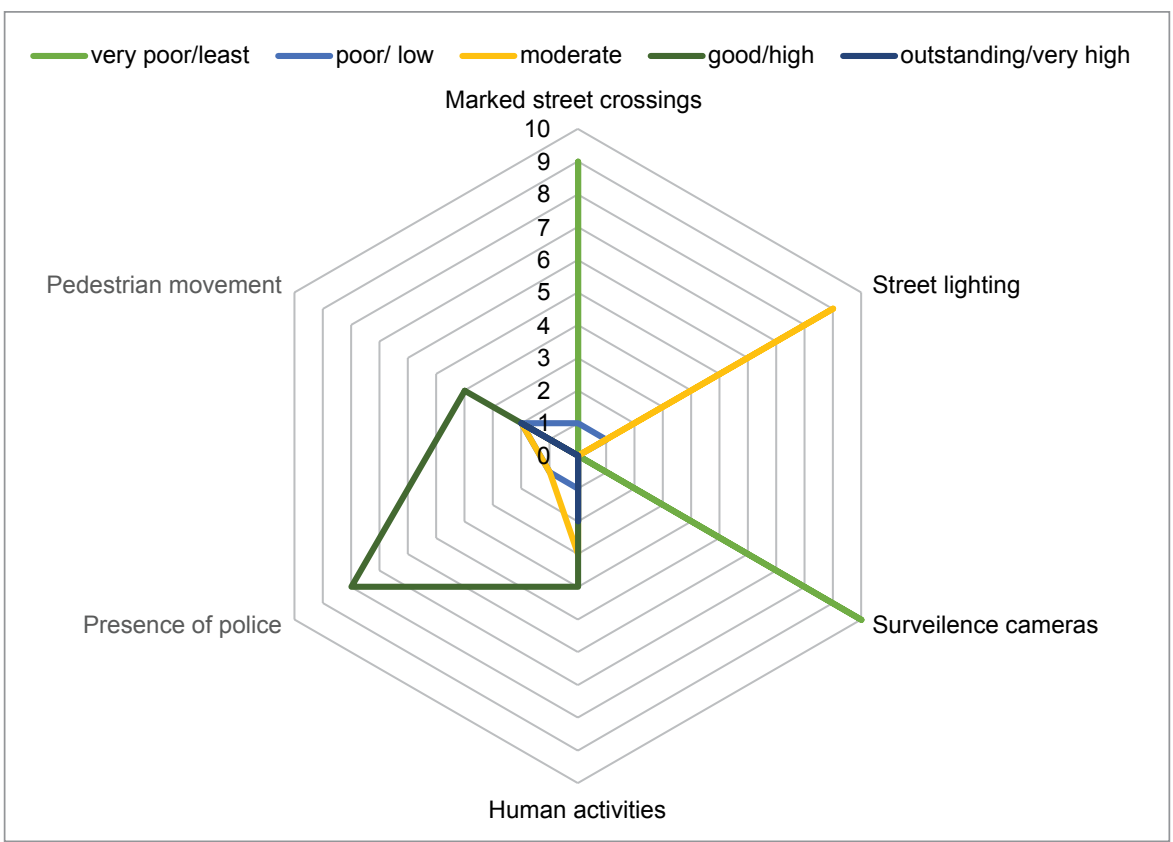

Source: Research survey (2020) 
Figure 3: Quality of Safety and Security features in Louis Trichardt

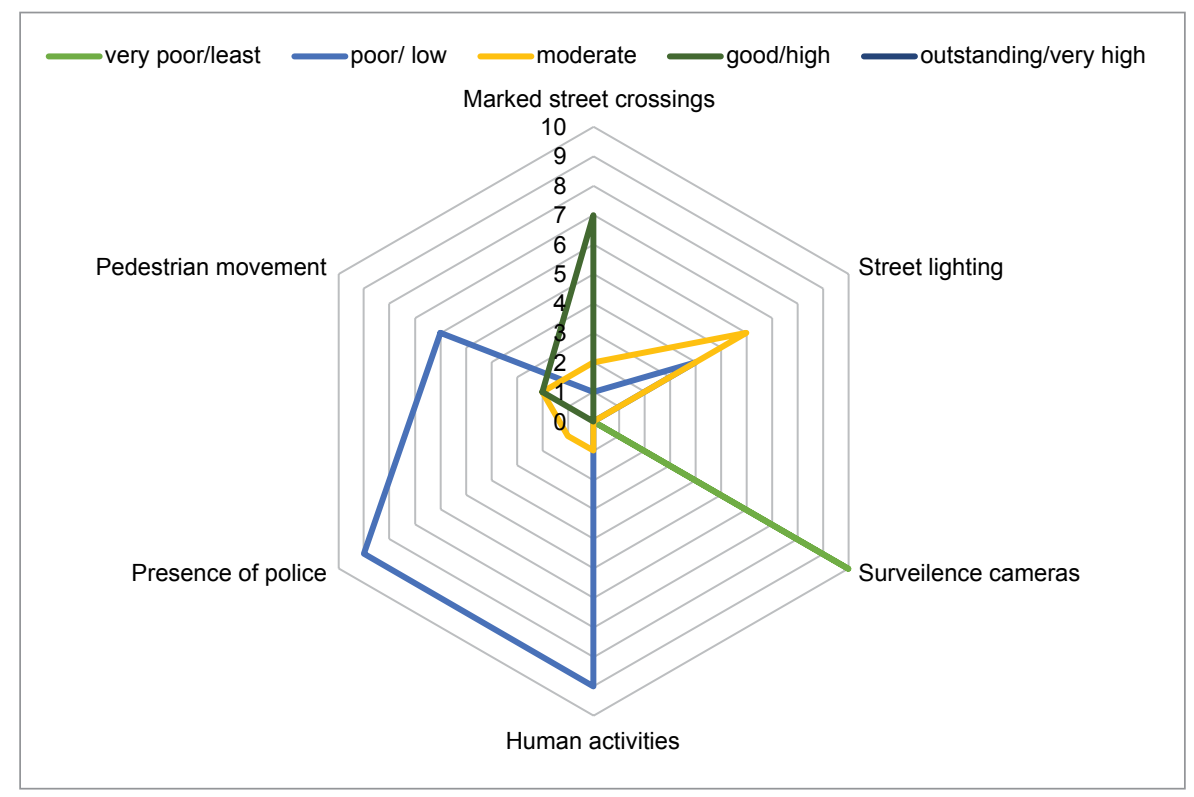

Source: Research survey (2020)

One of the safety elements analysed in the distribution of pedestrian safety and security elements on street spaces in the three SRTs is police presence. The assumption is that police presence providing surveillance on the street spaces makes the street safer and secure for its users. Police presence ranked very low in all streets in Thohoyandou and $80 \%$ of Louis Trichardt's streets. In contrast, the visibility of the police was high for all streets in Musina. The finding is attributed to national priorities on safety and security in border towns (Musina), unlike in non-border towns such as Thohoyandou and Louis Trichardt.

We also assessed the clarity of pedestrians' cross markings as another measure of street safety. The researchers assumed that the high-quality status of pedestrian cross markings' enhances street users' security and improves spatial justice (Kott 2011). The results show that $52 \%$ of the street spaces in Thoyoyandou had poor quality marked street crossings for pedestrians. In Musina, the pedestrian crossings were ranked very poor for over $90 \%$ of the streets. The absence of a marked crossing suggests that more priority is given to vehicular transport than pedestrians (Hartman and Pryteherch 2015). Responding to the issue of poorly marked pedestrian crossings, the municipal official from Musina Local Municipality said, "Our roads are now in need of reconstruction as day to day maintenance no longer suffices. However, we are resources strapped to effectively conduct regular maintenance, as we would want to, more so to carry out new projects. N1(the national highway), on the other hand, is maintained by a SANRAL, a private contractor on behalf of the National Department of Transport". The finding suggests that funding impacts street spaces' quality, resulting in either spatial justice or injustice. In contrast to the low quality of pedestrian crossing marks in Thohoyandou and Musina, in Louis Trichardt, pedestrian crossing markings' quality was high in $70 \%$ of the streets. This was attributed to the local municipalities' street maintenance routines that are more efficient in comparison to that of Musina and Thohoyandou Towns. The local municipality official for Makhado Local Municipality also added that Makhado Local Municipality obtained more revenue from own-source strategies in comparison to Thulamela and Musina Local Municipalities.

Camera surveillance was absent in all the streets in all towns; thus, they were ranked very poor. Although N1 (a national road) passes through Musina CBD, it lacks surveillance cameras. This was an unexpected finding as the $\mathrm{N} 1$ freeway is considered an important road linking South Africa to most African countries. Therefore, safety measures along N1 should be distinct. Discussions with municipality officials from all three towns showed a bias against street cameras' importance in ensuring overall street safety and security. They indicated that cameras are useful private property for shop owners who continuously monitor their property activities; however, they do not stop crime on the streets. As an alternative, the officials proposed more police visibility and more visible road marking. While Shaftoe (2008) advocates for place ambassadors, the local municipalities officials advocated for more police visibility. This difference between municipal officials' views and international researchers confirm that there are contextual differences in defining safety and security determinants.

The study assumed that good street lighting provides users with a better sense of safety and security. The quality of street lighting in Thohoyandou Town ranged from poor in some lower-order streets to moderate in higher-order streets (i.e. provincial distributor roads 
like R523 and R524). Some streetlights were not serviced and could not provide lighting for the night-time street users. The finding also reveals that the local municipalities prioritise street lighting maintenance in higher-order compared to lower order streets. On the contrary, the quality of street lighting was high in $70 \%$ of the streets (including lower-order streets) in Louis Trichardt Town.

Continuity of pedestrian movement, as a determinant of street space safety, was also assessed. Continuity of pedestrian movement in Thohoyandou Town ranged from moderate to outstanding in at least $73 \%$ of the street spaces. Since Thohoyandou Town is an administrative town for the Vhembe District Municipality, therefore it attracts many street users and sustains pedestrians' continuous movement. This ensures that there are natural surveillance methods on the streets. As argued in Jacobs (1961), pedestrians' constant movement ensures that there are "eyes on the street". In Musina Town, the visibility of human activities and the flow of pedestrians was notably high. The high and continuous flow of pedestrians in Musina Town owes to vibrant trade activities since it is a vibrant border town that attracts daily traders from neighbouring countries such as Zimbabwe and Mozambique (Musina Local Municipality, 2015).

In contrast, pedestrian movement on street spaces was low in Louis Trichardt Town. Deliberations with an official from Makhado Local Municipality revealed that Louis Trichardt Town has a low economic vibrancy in comparison to the Administrative town of Thohoyandou and the border town of Musina is the Northern gateway that attracts users from other neighbouring countries. This is due to the relocation of major companies to other towns such as Polokwane and Thohoyandou. The relocation of large businesses reduces the city's economic activity and, consequently, pedestrian volumes on the streets. It is anticipated that some recent developments such as the construction of a new mall (Makhado Crossing) and the establishment of a sub-campus for the University of South Africa, improved vibrancy of human activities and continuous movement of the pedestrians will be evidenced in Louis Trichardt Town.

\subsection{Hierarchical cluster analysis of safety and security in the three small rural towns}

To understand the different types of clusters that emerge from evaluating safety and security, we performed the HCA on all the 43 street spaces in the three SRTs. The dendrogram in Figure 4 illustrates three safety and security clusters that emerged from hierarchical cluster analysis.

\section{Figure 4: Safety and Security Clusters in the Three Towns}

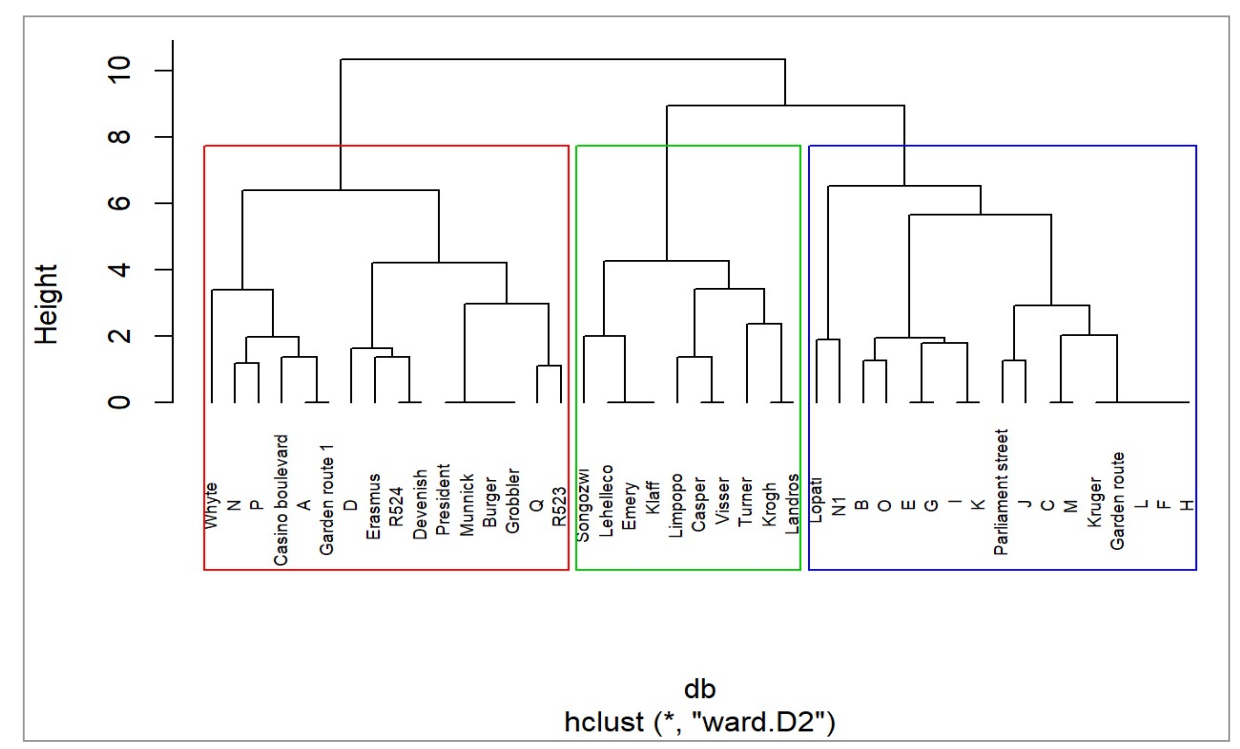

Source: Research survey (2020)

The dendrogram (Figure 4) comprises Cluster 1 (with $40 \%$ of the street spaces from Thohoyandou, 10\% from Musina and $60 \%$ from Louis Trichardt Town); Cluster 2 (with $60 \%$ of the streets from Thohoyandou, $20 \%$ from Musina and $10 \%$ from Louis Trichardt); and Cluster 3 (with $70 \%$ of the street spaces from Musina, and 30\% from Louis Trichardt). In understanding each cluster's performance, we computed standardised mean z-scores for each indicator. The results are shown in Table 1. 
Table 1: Street spaces cluster means for safety and security

\begin{tabular}{|l|l|l|l|}
\hline Variables & Cluster 1 & Cluster 2 & Cluster 3 \\
\hline Street crossing & 0.506308 & 0.19061 & -1.13413 \\
\hline Street lighting & 0.04943 & 0.103378 & -0.09666 \\
\hline Visibility of other human activities & -0.76431 & 0.696562 & 0.038734 \\
\hline Presence of police within the visibility & -0.53093 & -0.40884 & 1.544518 \\
\hline The continuous movement of pedestrians & -0.98348 & 0.793398 & 0.224796 \\
\hline Averages & -0.36437 & 0.275021 & 0.115452 \\
\hline Ranking & 3 & 1 & 2 \\
\hline
\end{tabular}

Source: Research survey (2020)

The average $z$-scores for Cluster 1 is the negatively performing Cluster $(z=-0.3643)$, implying the poorest in quality of safety and security features, followed by Cluster 3 (which has low positive performance $(z=0.1155)$ and Cluster 2 (which has high positive performance $(z=0.2750)$. These differences in the assessed measures of safety and security qualities suggest the variability of spatial justice. Cluster 1 ( $z=0.506308)$ streets have the highest score on clearly marked street crossings when compared to streets in Cluster $2(z=0.19061)$ and cluster $3(z=-1.13413)$. Although the street lighting performance in Cluster 1 ( $z=0.04943)$ has a positive score, it was lower than street lighting under Cluster 2 ( $z=0.103378)$. All other indicators in cluster 1 (visibility of other human activities ( $z=-0.76431)$; the presence of police within the visibility $(z=-0.53093)$; and the continuous movement of pedestrians $(z=-0.98348)$ have negative mean scores signifying poor safety and security of streets. The negative values suggest spatial (in)justice in Cluster 1, consisting of 16 streets dominated by Louis Trichardt.

In Cluster 2, dominated by Thohoyandou, street lighting ( $z=0.103378$ ), visibility of other human activities ( $z=0.696562)$, and continuous pedestrian movement $(z=0.793398)$ have positive mean scores, suggesting spatial justice. In contrast, the presence of police is poor ( $z=-0.40884)$ in cluster 2 . Cluster 3 (dominated by street spaces from Musina) ranked second in terms of cluster performance. Although cluster 3 has an overall positive mean score $(z=0.1155)$, its overall performance is lower than cluster 2 $(z=0.275021)$. The indicators of street crossing $(z=-1.13413)$ and street lighting $(z=-0.09666)$ had negative mean scores in this cluster (Cluster 3$)$, while police visibility has the highest mean score of 1.544518 .

\subsection{Users perceptions of street safety and security}

In assessing the users' perceptions of street safety and security, the main assumption was that if users are satisfied with the various safety and security measures on streets, then users are enjoying their right to be safe on street spaces, which translates to spatial justice. Table 2 presents the findings assessing the users' physical perceptions of street safety and security in SRTs.

Table 2: Users' perceptions of satisfaction with safety and security measures

\begin{tabular}{|l|l|l|}
\hline Variables & mean satisfaction score & SD \\
\hline The presence of police & 2.90 & 1.367 \\
\hline The presence of other street users & 4.15 & 0.919 \\
\hline Street lighting at night & 2.87 & 1.365 \\
\hline Street crossing & 2.86 & 1.385 \\
\hline Absence of cameras & 2.23 & 1.122 \\
\hline Fences on roadside & 2.42 & 1.245 \\
\hline & $\Sigma 17.43$ & \\
\hline
\end{tabular}

Source: Research survey (2020)

Table 2 shows the three SRTs case studies' overall results, with a mean satisfaction score of 17.43 , which is less than the midpoint mean score of 18 . The study reveals that participants were dissatisfied with various safety and security measures in the three SRTs (Thohoyandou, Musina and Louis Trichardt). The finding suggests that street space users in the three SRTs are not 
enjoying their spatial claim of safety and security on street spaces (which is a form of spatial (in)justice). The presence of other users is the most outstanding indicator in the towns (mean score of 4.15). This finding implies that 'eyes on the street' are a principal element in ensuring street safety, as earlier alluded to in Jacob (1960).

Wilcoxon rank-sum was used to test the study hypothesis of a statistically significant difference between the users' theoretical meaning of safety and security and their actual satisfaction with this quality as they use streets spaces. The results are shown in Table 3.

\section{Table 3: Users' perceived theoretical meaning and satisfaction with safety and security}

\begin{tabular}{|c|c|c|c|}
\hline $\begin{array}{l}\text { Distributions } \\
\text { compared }\end{array}$ & Z-statistic & $p$-value & Interpretation \\
\hline $\begin{array}{l}\text { Satisfaction with } \\
\text { street safety } \\
\text { The perceived } \\
\text { theoretical } \\
\text { meaning of street } \\
\text { safety }\end{array}$ & 5.0380 & 0.0000 & $\begin{array}{l}\text { Reject the null } \\
\text { hypothesis in } \\
\text { favour of the } \\
\text { alternative for all } \\
\text { the distributions } \\
\text { compared }\end{array}$ \\
\hline
\end{tabular}

Source: Research survey (2020)

Table 3 shows a p-value of 0.00 . Therefore, we reject the null hypothesis in favour of the alternative. This confirms the above hypothesis. It also proves that the theoretical interpretation or users' expectation of a variable often differs from their real experience.

\section{DISCUSSION}

The differences in the quality of safety and security indicators on street spaces between the towns are attributable to variations in maintenance and management philosophies. A local municipality maintenance routine influences the quality of street lighting and pedestrian cross markings. This is revealed in the case of Louis Trichardt Town. Its performance in the qualities of street lighting and pedestrian cross markings was higher in comparison to the other two towns because it has a more consistent maintenance routine. In their study on prioritisation of pedestrians needs' in Thiruvananthapuram city of India, Bivina and Parida (2019) concur that consistency in carrying out street maintenance improves the safety and security of streets.

Municipal officials dismissed the relevance of surveillance cameras as a measure of safety and security from all three towns. There exist contextual differences in the prioritisation of various safety elements between developed and developing countries (Bivina and Parida, 2019; Cozens, 2011). For example, Glassgow UK has extensive technological methods of monitoring its citizens' behaviour on the streets (Fyfe and Bannister, 1998: 254), while such technologies are lacking in the case study SRTs. This shows that spatial justice in terms of street safety and security is contextual and is often marked with dynamic contradictions between theory and practice in the case of the Global North viz-a vi the Global South (Soja, 2009).

Funding can be a hindrance or an enabler of the maintenance of public spaces to ensure street safety and security. This is evidenced in the case of Musina Town where the Municipal official indicated that inadequate funding not only affects the day-to-day maintenance but it also affects the implementation of new projects on improving street spaces. It was also established that public-private partnerships on street maintenance exist at the national level as evidenced in the case of N1(the national highway) where SANRAL a private company is responsible for its maintenance. Further, the discussions with a Musina Municipality official reveal that at the local municipality level such Private-Public Partnerships are lacking. Sustainable partnerships between local municipalities, the public, NonGovernmental Organisations, and the private sector are important in mobilising resources that municipalities require in creating more just street spaces (UCLG, 2013).

Deliberations with a Makhado Local Municipality revealed that the higher volumes of pedestrian movements experienced in Thohoyandou and Musina Towns contrary to Louis Trichardt were due to the variations in economic functions and geographical factors. For example, Thohoyandou attracts many users from around the district because of its administrative function in Vhembe District. While the geographic location of Musina Town, as a border town, also attracts users from neighbouring countries. This is confirmed by (Mustafa et al., 2017) who argues that a town's economic functions can have both positive and negative influence on street safety and security. For example the iconic role of Cairo in the Middle East (Mustafa et al., 2017).

The overall picture from HCA shows that Thohoyandou Town has the highest level of safety and security, followed by Musina Town. In contrast, Louis Trichardt Town has the least safety and security elements. In the various street clusters, some safety and security indicators were poorly performing on the street spaces, while others were strong within the same street. The similarities and variations in the level of street safety and security for streets within the same town as well as between towns reveal that street spaces in SRTs are not entirely homogenous spaces. They have different hierarchical levels and assume different functions. For example, the issue of street lighting in Thohoyandou Town reflected differently on higher-order streets in comparison to lower-order streets. The similarities and variations also reveal the spatial justice paradox highlighted by Erdiaw-Kwasie and Basson (2018), that no geography is completely even. More injustices in 
the distribution of the quality of safety and security elements were measurable on the street spaces in the SRTs than justices.

It is revealed from the user's different mean satisfaction scores that users' have different perceptions of street safety and security in the same space (Rezafar and Turk, 2018; Bivina and Parida, 2019). This reveals that street users experience the right to safe public space differentially (Tsoriyo, 2021). The notion of "eyes on the street" which was propounded by Jacobs (1960) in the United States, is still an important element of street safety and security, which is prioritised by users in the context of users in the SRTs. This shows that despite the evolving urban environment, street users still view other users' presence as important for ensuring street safety and security. The findings on the various users' satisfaction levels confirm that safety and security are complex measures of spatial justice. While some users' expressed satisfaction with one element, other users, on the other hand, experience injustice in the same space (Lefebvre, 1996). One can draw from these findings that spatial justice is a result of various contestations and negotiations on space (Loukaitou-Sideris and Ehrenfeucht, 2009). Therefore, the key producers of street spaces must consider the users' varying perceptions in producing spatially just street spaces (Bivina and Parida, 2019). The difference between users' expectations and their experiences, in reality, reveals that the processes of street design and management in SRTs, in some cases, fail to produce the expected justice outcomes on street spaces (DHS 2019). Hence the municipalities in the SRTs must improve the current street production processes in the SRTs to achieve the desired just outcomes.

\section{CONCLUSION AND RECOMMENDATIONS}

Based on the discussion of the key findings above, the basic requirements of safety and security that are negatively performing need to be improved, while the positively performing ones should be up-scaled accordingly in each of the case study SRTs. This can be done by exploring other innovative financing strategies that are not heavily reliant on the central government. These can include locally branded initiatives such as 'own a street' campaigns, where local municipalities engage local or international philanthropists to participate in funding street maintenance or other street improvement projects that account for spatially just street spaces.

Although users have differential perceptions of street safety and security, 'eyes on the street' are still considered integral to ensuring street safety by most sampled users. The study also confirms the hypothesis that a statistically significant difference between the users' theoretical meaning of safety and security and their actual satisfaction with this quality as they use streets spaces. To enhance spatial justice, street users (particularly pedestrians) should be viewed as keyspace producers and not mere recipients of produced spaces. Therefore, the design and maintenance of just street spaces should be informed by a clear safety and security vision and street users 'needs prioritisation. This is attained through engaging in contextappropriate and participatory users' needs prioritisation tools. In so doing, street users are more likely to be satisfied with the produced street spaces thus enjoy their right to safe public .spaces.

This study is not without its limitations; we could not obtain the views of SAPS, who are important in ensuring street safety and security because of the bureaucracy involved in obtaining permission to conduct the study. In concluding, we urge a more holistic approach in studying street spatial justice. Therefore, we propose a further study that includes other spatial qualities of measuring street space spatial (in)justice such as street accessibility, variety, legibility, and governance issues.

\section{DISCLOSURE STATEMENT}

We acknowledge the financial assistance of the National Research Foundation (NRF) through the Urban Resilience and Spatial Justice (NRF-URSJ) project. However, the opinions expressed and conclusions arrived at are those of the authors and are not necessarily attributed to NRF. 


\section{REFERENCES}

Adegeye, A. and Coetzee. J. 2019. "Exploring the Fragments of Spatial Justice and Its Relevance for the Global South." Development Southern Africa 36 (3): 376-89. https://doi.org/10.1080/0 376835X.2018.1495062.

Anderson, E. 2011. The Cosmopolitan Canopy: Race and Civility in Everyday Life. New York: WW Norton \& Company.

Atkinson, D. 2008. 'Inequality and Economic Marginalisation: Creating Access to Economic Opportunities in Small and Medium Towns'. TIPS. Available at: www.tips.org.za (Accessed: 20 February 2020).

Bivina, G.R. and Parida. M. 2019. "Prioritising Pedestrian Needs Using a Multi-Criteria Decision Approach for a Sustainable Built Environment in the Indian Context." Environment Development and Sustainability 22 (2020): 4929-50.

Carmona, M. Heath, Oc, T. Tiesdell.S. 2003. Public Places -Urban Spaces: The Dimensions of Urban Design. London: Architectural Place.

Council for Scientific and Industrial Research. 2016. "Making South Africa Safe: A Manual for Community Based Crime Prevention." Pretoria: Council for Scientific and Industrial Research.

Department of Human Settlements. 2019. The Neighbourhood Planning and Design Guide: Creating Sustainable Human Settlements. South Africa: Department of Human Settlements.

Dikeç, M. 2001. “Justice and the Spatial Imagination." Environment and Planning A: Economy and Space 33 (10): 1785-1805.

Dirsuweit, T. 2009. "New Urbanism, Public Space and Spatial Justice in Johannesburg: The Case of 44 Stanley Ave." Ann. Géo 665-666 (2009): 76-93.

Donnaldson, R. and Marias, L. 2012. 'Small Town Geography', in Donnaldson, R. and Marias, L. (eds) Small Town Geographies in Africa: Experiences in South Africa and
Elsewhere. New York: NOVA, pp. ixxviii.

Erdiaw-Kwasie, M.O. and M. Basson. 2018. "Re-Imaging Socio-Spatial Planning: Towards a Synthesis between Sense of Place and Social Sustainability Approaches." Planning Theory 17 (4): 514-532. https://doi. org/10.1177/1473095217736793.

Fowler, F. J. 2012. Research Methods. Thousand Oaks: SAGE.

Fyfe, N.R. and J. Bannister. 1998. "The Eyes Upon the Street: Closed Circuit Television Surveillance and the City." In Images of the Street: Planning, Identity and Title in Public Space, edited by N.R Fyfe, 254-67. London: Routledge.

Goodyear, S. 2013. "A New Way of Understanding Eyes on the Street." Available at: https://www.bloomberg. com/news/articles/2013-07-22/a-newway-of-understanding-eyes-on-thestreet (Accessed: 12 January 2020)

Government of South Africa. 2016. White Paper on Safety and Security. Government of South Africa.

Hamilton-Baillie, B. 2008. "Shared Space: Reconciling People, Places and Traffic." Built Environment 34 (2): 161-181.

Hartman, L.M. and D. Prytherch. 2015. "Streets to Live In: Justice, Space and Sharing the Road." Environmental Ethics 37 (1): 21-44.

Harvey, David. 2012. Rebel Cities: From the Right to the City to the Urban Revolution. London: Verso Books.

Hoogendoorn, G. and Visser, G. 2016. 'South Africa's Small Towns: A Review on Recent Research', Local Economy, 31(1-2): 95-108.

Imrie, R. 2012. "Auto-Disabilities: The Case of Shared Space Environments." Environment and Planning A 44 (9): $2260-2277$.

Jacobs, A. B. 1993. Great Streets. London: MIT Press.
Jacobs, J. 1961. The Death and Life of Great American Cities. New York: Random House.

Kott, J. 2011. "Streets of Clay: Design and Assessment of Sustainable Urban and Suburban Streets." PhD Thesis, Australia: Curtin University.

Lefebvre, H. 1996. 'Space: Social Product and Use Value', in Brenner, N. and Elden, S. (eds) State, Space, World: Selected Essays. Minneapolis: University of Minnesota Press, pp. 167-184.

Loukaitou-Sideris, A. and Ehrenfeucht, R. 2009. Sidewalks: Conflict and Negotiation over Public Space. Cambridge: MIT Press.

Lynch, K. 1960. The Image of the City. Cambridge: MIT Press.

Mehta, V. and Bosson, J. K. 2018. 'Revisiting Lively Streets: Social Interactions in Public Space', Journal of Planning Education and Research, pp. 1-13.

Ministry of Cooperative Governance and Traditional Affairs. 2016. Integrated Urban Development Framework. Government of South Africa

Moroni, S. 2020. 'The Just City: Three Background Issues: Institutional Justice and Spatial Justice, Social Justice and Distributive Justice, Concept of Justice and Conceptions of Justice', Planning Theory, 19(3): 251-267.

Musina Local Municipality. 2015. Musina Local Municipality Spatial Development Framework. South Africa: Musina Local Municipality.

Osóch, B. and Czaplińska, A. 2019. 'City Image Based on Mental Maps: The Case Study of Szczecin (Poland)', Miscellanea Geographica, 23(2), pp. 111-119.

Reynolds, K. and Antrobus, G. 2012 "Identifying Economic Growth Drivers in Small towns in South Africa." In Small town Geographies in Africa: Experiences in South Africa and Elsewhere, edited by R. Donnaldson and L. Marias, 35-44. New York: NOVA. 
Rezafar, A. and Turk, S.S. 2018. 'Urban design factors involved in the aesthetic assessment of newly built environments and their incorporation into legislation: The case of Istanbul.' Urbani izziv 29 (2):pp. 83-95.

Ritchey, T. 2013. 'Wicked Problems: Modelling Social Messes with Morphological Analysis', Acta Morphologica Generalis, 2(1): 1-8.

Shaftoe, H. 2008. Convivial Urban Spaces: Creating Effective Public Places. London: Earthscan.

SA Cities Urban Safety Reference Group. 2020. Public Space and Urban Safety. Urban Safety Brief No. 1/2020. Johannesburg: South African Cities Network

Shrestha, B. K. 2011. 'Street Typology in Kathmandu and Street Transformation', Urbani Izziv, 22(2), pp. 107-121.

Smith, H. and dos Santos, P.M. 2019. 8 Principles to better sidewalks. The City Fix. https://thecityfix.com/blog/8principles-better-sidewalks-hillary-smithpaula-manoela-dos-santos/(Accessed: 10 April 2020)

Soja, E.W. 2009. "The City and Spatial Justice." Available at: http://www.jssj. org.

South African Cities Network. 2014. Outside the Core: Towards An Understanding of Intermediate Cities in South Africa. Johannesburg: South African Cities Network.

South Africa Cities Network. 2019. "2018/19 Report: The State of Urban Safety in South Africa." Johannesburg.

Tsoriyo. W. W. 2021. Spatial (In) Justice and Street Spaces of Selected Small Rural Towns In Vhembe District of Limpopo Province, South Africa. (Unpublished doctoral thesis). University of Venda, Thohoyandou
United Cities and Local Governments (UCLG). 2013. Basic Services For All in An Urbanizing World: Third Global Report of United Cities and Local Governments on Local Democracy and Decentralization-GOLD III Executive Summary. Barcelona: UCLG.

Van Wyk, J. 2015. "Can SPLUMA Play a Role in Transforming Spatial Injustice to Spatial Justice in Housing in South Africa?" Southern African Public Law 30 (1): 26-41.

Weber, M., and I. Podnar Žarko. 2019. "A Regulatory View on Smart City Services." Sensors 19 (415): 1-18. https://doi.org/doi.org/10.3390/ s19020415.

Williams, J.M. 2013. "Towards A Theory of Spatial Justice." In Annual Meeting of the Western Political Science Association. Los Angeles. Los Angeles.

Wright, G. and Ribben, H. 2016.

Exploring The Impact of Crime on Road Safety in South Africa. Proceedings of the 35th Southern African Transport Conference (SATC 2016).Available at: http://hdl.handle.net/2263/57988 (Acceesed:10 January 2021)

World Bank. 2011. Crime and Violence in Central America: A Development Challenge. Latin America and the Caribbean. 
Notes 